\title{
Predators and livestock reduce bird nest survival in intensive Mediterranean farmland
}

\author{
Pedro Beja • Stefan Schindler • Joana Santana • Miguel Porto • Rui Morgado • \\ Francisco Moreira $•$ Ricardo Pita $•$ António Mira $\cdot$ Luís Reino
}

Received: 22 May 2013 /Revised: 17 September 2013 / Accepted: 8 October 2013 /Published online: 25 October 2013

(C) Springer-Verlag Berlin Heidelberg 2013

\begin{abstract}
High nest predation is one of the factors potentially driving farmland bird declines, particularly in the case of ground-nesting species. Accordingly, recent calls have been made to address predation in agri-environment schemes, but this is hindered by limited understanding of how processes operating at different scales affect predation patterns and how additional factors such as livestock trampling contribute to reduced nest survival. Using an artificial nest experiment, we assessed how field management, landscape composition and configuration, and the abundance of potential avian predators and mammalian carnivores affected predation and trampling rates in grassland fields (pastures and fallows) embedded in
\end{abstract}

Communicated by C. Gortázar

Electronic supplementary material The online version of this article (doi:10.1007/s10344-013-0773-0) contains supplementary material, which is available to authorized users.

P. Beja $(\bowtie) \cdot$ S. Schindler $\cdot$ J. Santana $\cdot$ M. Porto $\cdot$ L. Reino EDP Biodiversity Chair, CIBIO/InBio, Centro de Investigação em Biodiversidade e Recursos Genéticos, Universidade do Porto, Campus Agrário de Vairão, 4485-601 Vairão, Portugal e-mail: pbeja@cibio.up.pt

S. Schindler

Department of Conservation Biology, Vegetation and Landscape

Ecology, University of Vienna, Rennweg 14, 1030 Vienna, Austria

R. Morgado $\cdot$ F. Moreira

CEABN/InBio, Centro de Ecologia Aplicada "Professor Baeta

Neves", Instituto Superior de Agronomia, Universidade Técnica de

Lisboa, Tapada da Ajuda, 1349-017 Lisbon, Portugal

R. Morgado

ERENA-Ordenamento e Gestão de Recursos Naturais SA, Rua

Robalo Gouveia, 1-1A, 1900-392 Lisbon, Portugal

R. Pita $\cdot$ A. Mira

CIBIO/InBio, Centro de Investigação em Biodiversidade e Recursos Genéticos, Pólo de Évora, Universidade de Évora, Núcleo da Mitra, Apartado 94, 7002-554 Evora, Portugal intensive Mediterranean farmland. Mean predation and trampling rates per field were $0.18 \pm 0.23 \mathrm{SD}$ and $0.12 \pm 0.17$ $\mathrm{SD}$, respectively. However, there was strong spatial variation, with high nest losses $(>50 \%)$ occurring in about one quarter of the fields. Variation in failure rates was mainly related to livestock grazing and predator abundances, while the effects of landscape context were negligible. Predation and trampling rates were highest in fields with short swards. Predation rate was positively related to the abundance of Egyptian mongooses and dogs. To increase nest survival, agri-environment schemes designed for ground-nesting birds should contribute for maintaining low stocking density. Further evaluation is required on the need for controlling populations of fastexpanding generalist predators such as mongooses.

Keywords Agri-environment schemes $\cdot$ Artificial nest experiment · Grassland bird · Grazing · Nest predation · Trampling

\section{Introduction}

Agricultural intensification is one of the leading causes of bird population declines across Europe (Donald et al. 2006). Although these declines have been mainly related to habitat changes that reduce food and nesting site availability, there is evidence that increased predation may also be playing a role (Evans 2004). As a consequence, there have been calls to address predation in agri-environment schemes designed to protect farmland birds (Van der Wal and Palmer 2008; Fletcher et al. 2010), but this is hindered by an incomplete understanding of how agricultural changes affect predation patterns.

Ground-nesting birds seem to be particularly vulnerable to agricultural intensification (Bas et al. 2009), which may be related, to some extent, to their high exposure to nest predation 